\title{
Urban Qualities in an Emerging Regional Metropolis: The Case of Doha
}

\author{
Authors Ashraf M. Salama, Florian Wiedmann, Alain Thierstein, Nina Alaily-Matar, \\ Sven Conventz \\ Institutions Qatar University, Doha, Qatar \\ Institute of Spatial and Territorial Planning, Munich University of \\ Technology, Germany \\ e mail asalama@qu.edu.qa
}

Since the late 1990s, Qatar and its capital city Doha have been undergoing a new period of urbanization. Doha is viewed as an important emerging city in the Gulf region with a growing potential to constitute knowledge economies as a foundation for its future prosperity. Driven by economic diversification strategies that aim to establish the city as a global service hub, sport and media events and cultural facilities are being developed in order to brand the city as an international service center. This contribution aims at introducing a responsive framework for analyzing the complex inter-dependencies between knowledge economies and physical urban developments in Doha. In this respect, this is an ongoing research process, as part of a QNRF-NPRP funded project, which seeks to deliver insights into the complexity of the various factors that produce urban space and their individual effects on urban qualities. Based on Henri Lefebvre's triad of space production (conceived-perceived-lived), a framework has been developed and particularly devised to explore the inter-dependencies of Doha's recent economic transformation and the changing structure of its urban environment. The framework involves comprehensive analysis of urban planning decision making processes as well as in-depth investigation that applies interlocking network models to examine how urban space is currently used by companies of new economic sectors. Taking into account the importance of the role played by the employees working in these companies and their perception of contemporary urban space in the city, the framework utilizes empirical research techniques that involve survey studies, focused interviews, and behavioral mapping. In addition to investigating the various factors driving spatial transformation, the evolutionary aspects of the city's urban structure are traced and analyzed using GIS data and space syntax studies. The results of implementing this framework are amenable to establish a comprehensive understanding of the potential and deficits of Doha's urban environment, which in turn, foster the city's aspirations in establishing a thriving knowledge economy. 